\title{
PENGEMBANGAN KEBIJAKAN KAWASAN EKO-INOVASI (STUDI KASUS KAWASAN PUSAT ILMU PENGETAHUAN DAN TEKNOLOGI, KOTA TANGERANG SELATAN)
}

\author{
Sri Setiawati ${ }^{1}$, Hadi Alikodra ${ }^{2}$, Bambang Pramudya ${ }^{2}$, dan Arya Hadi Dharmawan ${ }^{2}$ \\ ${ }^{1}$ Kemenristek dan Dikti \\ ${ }^{2}$ Departemen Pengelolaan Sumber Daya Alam dan Lingkungan IPB \\ Email:asdep42@yahoo.com
}

\begin{abstract}
Secara konsep, strategi dan paradigma yang berkaitan dengan pembangunan berkelanjutan, baik pada level makro, meso maupun mikro sudah mampu menggeser paradigam lama seperti paradigma pertumbuhan ekonomi sampai pada tahun 1970 dan paradigma yang menekankanpada aspek pemerataan hasilhasil pembangunan. Namun demikian, dalam tataran implementasi sampai saat ini belum memberikan hasil yang menggembirakan. Oleh karena itu dalam pertemuan KTT Rio+20 tahun 2012 mendeklarasikan dokumen baru pembangunan berkelanjutan dengan judul "The Future We want". The Future We Want yang menekankan kepada semangat bersama walaupun berbeda tanggung jawab, dan menekankan pada pembangunan ekonomi hijau yang lebih dapat diterima oleh para pelaku ekonomi. Kawasan PUSPIPTEK yang memiliki lahan seluas 460 hektar sampai saat ini masih terjaga sebagai kawasan hijau dengan ruang terbuka hijau lebih dari tiga puluh persen. Kawasan PUSPIPTEK memiliki lahan seluas 460 Ha sampai saat ini masih terjaga sebagai kawasan hijau dengan ruang terbuka hijau lebih dari 30 persen. Berpedoman pada konsep-konsep yang dikembangkan dalam menjadikan kawasan menjadi kawasan ekologi , maka Pusat Ilmu Pengetahuan dan Teknologi sebagai sebuah kawasan yang memiliki 47 Balai / Pusat / laboratorium, industri berbasis teknologi serta sarana pendukung publik dimana di dalamnya terdapat 5 institusi meliputi Kementerian Ristek, BPPT, LIPI, Batan serta Kementerian Lingkungan Hidup dapat dilihat sebagai model eko-inovasi dimana terjadi aliran proses dan produk. Tujuan penelitian adalah menyusun pengembangan kebijakan eko-inovasi pada kawasan PUSPIPTEK. Selanjutnya untuk mengembangkan model pengelolaan eko-inovasi digunakan Analytical Hierarchy Process (AHP) dan Intrepretative Structural Model (ISM) digunakan untuk pengembangan model kelembagaan eko-inovasi. Hasil penelitian ini menunjukkan bahwa model pengelolaan yang dipilih adalah model pengelolaan partnersip (kemitraan) dimana hal ini sesuai dengan harapan pemangku kepentingan di kawasan PUSPIPTEK. Sementara itu, untuk mengembangkan kelembagaan eko-inovasi telah diidentifikasi ada 6 elemen yang memegang peranan penting meliputi; partisipasi pemangku kepentingan, sistem perencanaan, biaya pengelolaan lingkungan, prilaku stakeholder, kualitas SDM dan aturan pengelolaan limbah. Dengan demikian, untuk dapat mengimplementasikan konsep eko-inovasi di kawasan PUSPIPTEK diperlukan restrukturisasi kelembagaan PUSPIPTEK.
\end{abstract}

Key words : Eko-inovasi, kebijakan, AHP, ISM

\section{POLICY DEVELOPMENT OF ECO-INNOVATION PARK (CASE STUDY: CENTER OF SCIENCE AND TECHNOLOGY PARK, SOUTHTANGERANG) ${ }^{1}$}

\begin{abstract}
ABSTRAKConceptually, strategies and paradigms relating to sustainable development, both at the macro, meso or micro level are able to shift the long standing paradigm as of economic growth until the 1970s and paradigm highlight on aspects of equitable development outcomes. However, in the level of implementation that have not provided results are encouraging. Therefore, in the Rio + 20 SUMMIT meeting 2012 have been declaring new document of sustainable development under the title "The Future We Want". The Future We Want to emphasize that the spirit togetherness despite different responsibilities, and the emphasisze on green economic development more acceptable by the stake holder of Economics. The PUSPIPTEK Area has 460 hectares of land still awake as the greenery with open green space of more than thirty percent. Based on the concepts developed in the region be made eco-region, then the center of science and technology as an area has 47 Center/laboratory, technology-based industries as well as a means of supporting the public in which there are 5 institutions include Ministry of research \& technology, BPPT, LIPI, Batan as well as the Ministry of environment can be seen as a model of eco-innovation which occurs the flow of processes and products. The purpose of the study is to set up policy development of ecoinnovation in the area of PUSPIPTEK. Further, the study used Analytical Hierarchy Process (AHP) method to develop eco-innovation management models and Intrepretative Structural Model (ISM) is used for the development of the institutional of eco-innovation model. The results of this study show that the chosen management model is a model of managing partnership (partnership) which is in accordance with the expectations of the stakeholders in the area of PUSPIPTEK. In the meantime, to develop institutional eco-innovation has been identified there are 6 elements that play an important role include; the participation of stakeholders, systems planning, environmental management, cost behavior of stakeholders, the quality of human resources and management of waste. Thus, to be able to implement the concept of eco-innovation in PUSPIPTEK that needs restructuring of institusional PUSPIPTEK.
\end{abstract}

Key words: eco-innovation, policy, AHP, ISM 


\section{PENDAHULUAN}

Secara konsep, strategi dan paradigma yang berkaitan dengan pembangunan berkelanjutan, baik pada level makro, meso maupun mikro sudah mampu menggeser paradigam lama seperti paradigma pertumbuhan ekonomi sampai pada tahun 1970 dan paradigma yang menekankan pada aspek pemerataan hasil-hasil pembangunan (Arifin 2012). Namun demikian,dalam tataran implementasi sampai saat ini belum memberikan hasil yang menggembirakan sehingga terjadi ketimpangan antara negara maju dan negara berkembang. Oleh karena itu dalam pertemuan KTT Rio+20 tahun 2012 mendeklarasikan dokumen baru pembangunan berkelanjutan dengan judul"The Future We want". The Future We Want yang menekankan kepada semangat bersama walaupun berbeda tanggung jawab, dan menekankan pada pembangunan ekonomi hijau yang lebih dapat diterima oleh para pelaku ekonomi.

Konsep baru berupa eko-inovasi lebih bersifat ekslusif, tidak hanya berkaitan dengan aspek teknis lingkungan, tetapi lebih dari pada itu yakni masuk pada ranah manajemen, kebijakan serta sosial inovasi. Konsep eko-inovasi menurut OECD (2011) adalah sebagai penciptaanatau penerapan baru, atau meningkatkansecara signifikan, produk (barang dan jasa), proses, metode pemasaran, struktur organisasi dan kelembagaan, serta aturan yang bertujuan agar terjadinya perbaikan lingkungan dibandingkan dengan alternatif yang relevan.

Sarkar(2013) menyimpulkan bahwa dari berbagai definisi yang berkembang konsep eko-inovasi dapat dibagi menjadi dua kategori, inovasi lingkungan dan inovasi non-lingkungan.Dalam hal pengembangan, inovasi lingkungan berkelanjutan menjadi hal yang sangat penting. Konsep ini juga dapat diklasifikasikan menjadi teknologi eko-inovasi, eko-inovasi organisasi, inovasi terkait dengan kawasan bisnis dan inovasi sosial. Pada level kawasan, kawasan Eko-Industri dapat pula disebut sebagai kawasan eko-inovasi dimana Sakr et al. . (2011) menyatakan faktor penentu keberhasilan kawasan eko-industri di seluruh dunia adalah adanya hubungan kerjasama kemitraan, nilai tambah ekonomi, kebijakan dan peraturan, kesadaran dan informasi, pembentukan kelembagaan dan organisasi, serta faktorfaktor teknis.

Seiring dengan munculnya kesadaran dunia pada kelestarian lingkungan maka kebijakan-kebijakan yang dibuat juga sudah mengarah pada kebijakan yang berupaya mengimplementasikan pembangunan berkelanjutan. Oleh karena itu kata-kata yang menunjukkan sudah ramah lingkungan seperti kata green atau eko, misalnya eko-inovasi sudah tidak asing lagi bagi kita. Namun demikian penelitian-penelitian yang telah dilakukan lebih banyak mengarah pada industri yang dilakukan oleh Adamides et al. (2009), Anderson (2004, 2005, 2006), Era-Net Eco-Innovera (2012); Jones et al.(2001), OECD (2009), Pansera (2013), Sarkar (2013), Sakr et al. (2011, Tian et al. (2013) dan Zaenuri (2009) semuanya mengarah pada industri. Hanya ada satu penelitian yang terkait dengan Pusat kajian teknologi yakni penelitian Alkadri et al. (1999) tentang manajemen teknologi untuk pengembangan wilayah Pusat Pengkajian Kebijakan Teknologi Pengembangan Wilayah, BPPT; sedangkan penelitian pengembangan kebijakan ekoinovasi di Pusat Penelitian Ilmu Pengetahuan dan Teknologi belum pernah dilakukan.Oleh karena itu, dengan mengimplementasikan hasil inovasi di dalam kawasan serta menerapkan sistem organisasi eko, maka diharapkan terwujud penerapan hasil inovasi teknologi hijau di kawasan sebagaiupaya mewujudkan pembangunan yang berkelanjutan.

Tujuan penelitian adalah menyusun pengembangan kebijakan eko-inovasi pada kawasan PUSPIPTEK. Untuk dapat menyusun pengembangan kebijakan ekoinovasi Kawasan PUSPIPTEK,perlu disusun:

1. Sistem pengelolaan eko-inovasi Kawasan PUSPIPTEK.

2. Struktur lembaga eko-inovasi Kawasan PUSPIPTEK.

Eko-inovasi merupakan pendekatan baru yang diterapkan di dunia industri dalam rangka mengatasi kerusakan lingkungan dan upaya mempertahankan keberlanjutan ekosistem. Studi yang berkaitan dengan kebijakan eko -inovasi di Kawasan PUSPIPTEK belum pernahdilakukan. Terkaitdengan eko-inovasidiKawasan PUSPIPTEK ada tiga kekhususan yang diidentifikasi dalam eko-inovasi meliputi: 1) permasalahan yang kompleks;; 2) merumuskan pengembangan kebijakan yang dapat diimplementasikan dilokasi eko-inovasi layak diterapkan dan bermanfaat untuk pembangunan lingkungan yang berkelanjutan. Oleh karena itu, dalam pengembangan eko-inovasi diperlukan adanya sinergi antara kebijakan inovasi dan kebijakan lingkungan. Adapun yang menjadi faktor krusial dan penting adalah dalam hal meningkatkan arti pentingnya kelembagaan eko inovasi yang akan memberikan dampak yang baik bagi semua pemangku kepentingan.Oleh karena itu, kebaruan dan kemutakhiran penelitian ini adalah:

1. Penelitian pada kawasan spesifik, Pusat Penelitian dan Pengembangan Iptek sebagai obyek vital serta strategis nasional, memiliki kompleksitas yang sangat tinggi dalam pengelolaan kawasan, sehingga perlu dirumuskan dalam sistem yang terpadu. Hal ini disebabkan pada kawasan tersebut terdapat obyek vital instalasi reaktor penelitian nuklir serta pusat-pusat penelitian seperti fisika, kimia, bioteknologi serta penelitian lainnya yang membutuhkan kebijakan pengelolaan lingkungan yang terintegrasi agar masyarakat yang ada di dalam kawasan maupun luar kawasan memiliki rasa aman dan nyaman. Penelusuran literatur yang dilakukan penulis memperlihatkan bahwa penelitian Pengembangan Kebijakan eko- inovasi pada kawasan PUSPIPTEK ini belum pernah dilakukan. Oleh karena itu dari aspek pendekatan konsep dan lokasi penelitian memiliki kebaruan.

2. Pengembangan sub model kelembagaan eko-inovasi di Kawasan PUSPIPTEK yang memadukan antara sistem pengelolaan kawasan 
eko-inovasi dan struktur lembaga memberikan dimensi baru dalam mewujudkan kerangka kebijakan eko-inovasi. Agar konsep ekoinovasi dapat diimplementasikan di Kawasan PUSPIPTEK, maka restrukturisasi kelembagaan harus dilakukan agar mampu menghela tujuan, fungsi dan peran PUSPIPTEK dalam penerapan eko-inovasi.

Untuk dapat menyusun pengembangan kebijakan eko-inovasi yang strategis di kawasan PUSPIPTEK, maka beberapa pertanyaan penelitian sebagai berikut :

1. Bagaimana sub model ekologis yang dihasilkan dari memadukan pengelolaan air, energi dan limbah dapat dirancang secara terpadu dengan konsep eko-inovasi?

2. Bagaimana sub model kelembagaan yang optimal dapat terwujud melalui integrasi dari sistem pengelolaan dan pengembangan struktur lembaga eko-inovasi dalam mengembangkan kawasan eko-inovasi PUSPIPTEK secara komprehensif?

3. Bagaimana pengembangan kebijakan eko-inovasi yang komprehensif pada kawasan PUSPIPTEK dapat terwujud?

Konsep eko-inovasi merupakan konsep baru. Komisi Eropa dalam mengukur ekonomi inovasi menggunakan definisi eko-inovasi sebagai "produksi, asimilasi atau eksploitasi produk, proses produksi, layanan atau manajemen atau metode bisnis yang baru untuk organisasi (mengembangkan atau mengadopsi itu) dan yang menghasilkan, sepanjang siklus hidupnya, pengurangan risiko lingkungan, polusi dan lainnya dampak negatif penggunaan sumber daya (termasuk penggunaan energi) dibandingkan dengan alternatif yang relevan".

Eko-inovasi didefinisikan oleh OECD (2009) pada Laporan Manufaktur Berkelanjutan dan Ekoinovasi sebagai penciptaan atau penerapan baru, atau secara signifikan ditingkatkan, produk (barang dan jasa), proses, metode pemasaran, struktur organisasi dan kelembagaan pengaturan yangdengan atau tanpa maksud menyebabkan terjadinya perbaikan lingkungan dibandingkan dengan alternatif yang relevan. Kedua, definisi yang sejalan dengan definisi Oslo Manual (2011) inovasi, meliputi implementasi teknologi baru yang dikembangkan oleh perusahaan atau lembaga yang berbeda. Menurut Oslo Manual (2011), perusahaan dapat berinovasi (eko-inovasi) dengan membeli teknologi produksi bersih dari pemasok dan menerapkan teknologi ke lini produksi. Oslo Manual menjadi penting karena digunakan sebagai pedoman untuk survei inovasi resmi dihampir semua negara-negara anggota OECD.

Menurut beberapa literatur kebijakan publik dalam kepustakaan Internasional disebut sebagai public policy, yaitu suatu aturan yang mengatur kehidupan bersama yang harus ditaati dan berlaku mengikat seluruh warganya. Setiap pelanggaran akan diberi sanksi sesuai dengan bobot pelanggarannya yang dilakukan dan sanksi dijatuhkan didepan masyarakat oleh lembaga yang mempunyai tugas menjatuhkan sanksi (Nugraha. 2004; 1-7).
Aturan atau peraturan tersebut secara sederhana kita pahami sebagai kebijakan publik, jadi kebijakan publik ini dapat kita artikan suatu hukum. Akan tetapi tidak hanya sekedar hukum namun kita harus memahaminya secara utuh dan benar. Ketika suatu isu yang menyangkut kepentingan bersama dipandang perlu untuk diatur, maka formulasi isu tersebut menjadi kebijakan publik yang harus dilakukan dan disusun serta disepakati oleh para pejabat yang berwenang. Ketika kebijakan publik tersebut ditetapkan menjadi suatu kebijakan publik; apakah menjadi Undang-Undang, apakah menjadi Peraturan Pemerintah atau Peraturan Presiden termasuk Peraturan Daerah, maka kebijakan publik tersebut berubah menjadi hukum yang harus ditaati.

Pakar kebijakan publik mendefinisikan kebijakan publik segala sesuatu yang dikerjakan atau tidak dikerjakan oleh pemerintah, mengapa suatu kebijakan harus dilakukan dan apa manfaat bagi kehidupan bersama harus menjadi pertimbangan yang holistik agar kebijakan tersebut mengandung manfaat yang besar bagi warganya dan berdampak kecil dan sebaiknya tidak menimbulkan persoalan yang merugikan. Walaupun demikian tetap saja ada yang diuntungkan dan ada yang dirugikan, pemerintah harus bijaksana dalam menetapkan suatu kebijakan (Dye 1992; 2-4).

Dalam rangka memahami kedudukan dan peran yang strategis dari pemerintah sebagai aktor publik terkait dengan kebijakan publik, maka diperlukan pemahaman bahwa untuk mengaktualisasikannya diperlukan suatu kebijakan yang berorientasi pada kepentingan rakyat. Aminullah dalam Muhammadi 2001: 371 - 372, seorang pakar mengatakan bahwa kebijakan adalah suatu upaya atau tindakan untuk mempengaruhi sistem pencapaian tujuan yang diinginkan, upaya dan tindakan dimaksud bersifat strategis yaitu berjangka panjang dan menyeluruh. Namun demikian

\section{METODE}

Penelitian model kebijakan pengembangan kawasan eco-inovasi pusat ilmu pengetahuan dan teknologi dilakukan di Kawasan Pusat Ilmu Pengetahuan dan Teknologi (PUSPIPTEK), Kota Tangerang Selatan. Penelitian ini dilaksanakan pada bulan Juni 2013 sampai dengan Desember 2013

Penelitian ini dilakukan dengan menggunakan tahapan sebagai berikut:

1. Tahap pendahuluan, meliputi kajian studi literatur dan sumber informasi yang dapat menunjang pelaksanaan penelitian, studi lapangan kondisi saat ini PUSPIPTEK meliputi kelembagaan yang ada, keberadaan Laboratorium balai dan fasilitas yang ada dan survei pendapat pakar.

2. Tahap desain model, dibangun melalui sub model kelembagaan yang dilakukan dengan memilih sistem pengelolaan kawasan eko-inovasi serta struktur lembaga

Dalam rangka mencapai tujuan penelitian akan dilakukan serangkaian teknik pengumpulan data sebagai berikut : 
1. Data tentang kondisi eksisting PUSPIPTEK meliputi data utilitas, data masterplan kawasan, data SDM, data kelembagaan LPNK dan Balai/ Laboratorium di PUSPIPTEK.

2. Pendapat pakar yang akan digunakan untuk perumusan pengembangan kebijakan eko-inovasi berasal dari pakar-pakar yang membidangi ekoinovasi Kriteria pemilihan pakar dilakukan berdasarkan kriteria menurut Marimin (2004) yaitu: (1) keberadaan pakar atau responden dan kesediaanya untuk dilakukan wawancara, (2) memiliki reputasi, kedudukan dan telah menunjukkan kredibilitasnya sebagai ahli atau pakar pada substansi yang diteliti, dan (3) telah memiliki pengalaman dalam bidangnya. Pakar yang diwawancara meliputi Perwakilan Lembaga Litbang di kawasan Puspiptek yaitu BPPT, LIPI, BATAN, Pusarpedal Kementerian Lingkungan Hidup, Kemenristek, Perwakilan Peneliti, Bappeda Kota Tangerang Selatan, Perwakilan Masyarakat Sekitar (Lurah dan Camat Cisauk dan Serpong).

3. Data sekunder dari berbagai publikasi ilmiah.

Teknik pengolahan data dilakukan dengan tahapan sebagai berikut:

a) Pemilihan model pengelolaan kawasan dengan menggunakan teknik AHP. Tujuannya untuk memilih model pengelolaan kawasan yang terbaik untuk diimplementasikan di PUSPIPTEK.

b) Perancangan struktur lembaga eko-inovasi dengan analisis ISM untuk mendapatkan struktur lembaga terbaik dalam pengelolaan kawasan PUSPIPTEK sebagai kawasan eko-inovasi.

c) Perancangan pengembangan kebijakan tentang pengembangan eko-inovasi yang akan diimplementasikan.

Teknik pengolahan data dilakukan dengan tahapan sebagai berikut:

1 Pemilihan model pengelolaan kawasan dengan menggunakan teknik AHP. Tujuannya untuk memilih model pengelolaan kawasan yang terbaik untuk diimplementasikan di Puspiptek.

2 Perancangan model lembaga eko-inovasi dengan analisis ISM untuk mendapatkan kelembagaan terbaik dalam pengelolaan kawasan Puspiptek sebagai kawasan eko- inovasi.

\section{HASIL DAN PEMBAHASAN}

Pemilihan alternatif pengelolaan kawasan ekoinovasidilakukan dengan menggunakan metode pengambilan keputusan AHP. Penilaian alternatif berdasarkan kriteria adanya regulasi dan kebijakan, dukungan teknologi, pendanaan dan kemampuan SDM dilakukan oleh pakar. Pakar tersebut melakukan penilaian terhadap alternatif berdasarkan kriteria adanya regulasi dan kebijakan, dukungan teknologi, pendanaan dan kemampuan SDM yang sudah dirumuskan. Alternatif model pengelolaan eko-inovasi Kawasan PUSPIPTEK yaitu sistem manajemen terpusat (sentralisasi), sistem manajemen berdasarkan klaster, sistem manajemen desentralisasi dan sistem manajemen partnership. Hirarkhi pemilihan alternatif model pengelolaan kawasan ekoinovasi disajikan pada Gambar 1.

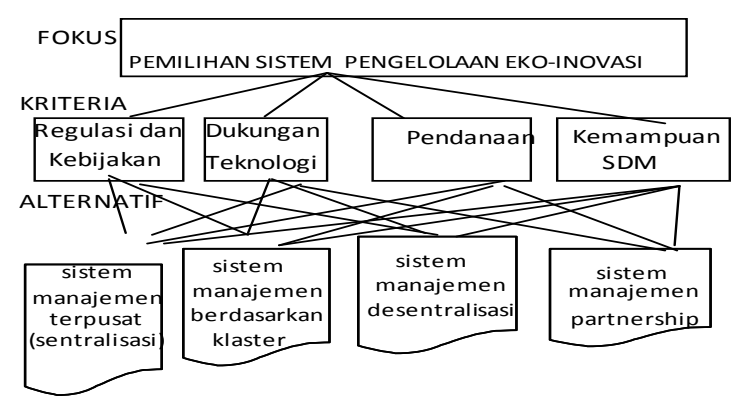

Gambar 1 Hirarki pemilihan pengelolaan kawasan ekoinovasi menggunakan metode AHP

Hasil pengolahan AHP yang dilakukan berdasarkan penilaian pakar disajikan pada Gambar 2. Untuk menentukan sistem pengelolaan eko-inovasi yang paling optimal, maka pada tahap awal ditentukan kriteria-kriteria yang dapat mempengaruhi terhadap pemilihan alternatif-alternatif yang ada. Berdasarkan hasil pakar maka ditentukan empat kriteria yang meliputi; aspek regulasi dan kebijakan, dukungan teknologi, pendanaan serta kemampuan sumber daya manusia. Pada kriteria ditentukan prioritas yang paling mempengaruhi terhadap model pengelolaan kawasan eko-inovasi. Hasil pengolahan data yang diambil dari wawancara para pakar memperlihatkan regulasi dan kebijakan adalah merupakan kriteria yang paling dominan dengan nilai 0,329 , prioritas kedua dukungan teknologi dengan nilai 0,282, prioritas ketiga pendanaan dengan nilai 0,215 dan kemampuan SDM dengan nilai 0,173 dengan konsistensi rasio sebesar 0,044. Hasil secara lengkap disajikan pada Gambar 2. Untuk implementasi eko-inovasi ini memerlukan payung regulasi dan kebijakan untuk dapat menjalankannya sehingga ada kesinambungan dalam implementasinya.

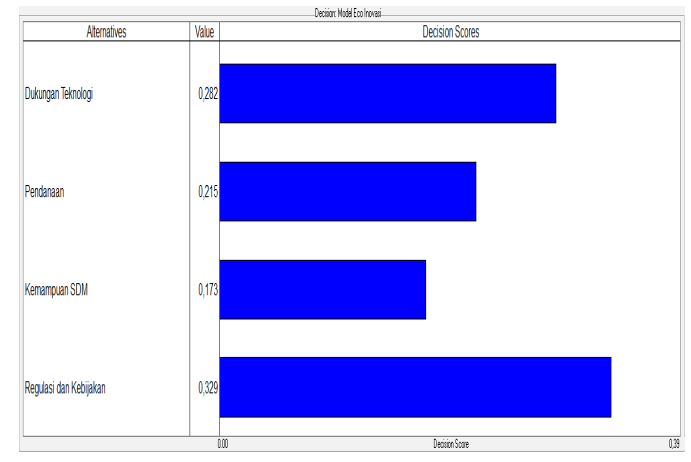

Gambar 2 Hasil pengolahan AHP prioritas kriteria pemilihan sistem pengelolaan ekoinovasi

Selanjutnya, berdasarkan pakar maka sistem pengelolaan Kawasan Eko-Inovasi yang paling sesuai adalah sistem partnership dengan nilai 0,442 , model sentralisasi dengan nilai 0,245 , model klaster dengan nilai 0,167 dan model desentralisasi dengan nilai 0,146 dengan konsistensi rasio 0,022. Hasil analisis disajikan pada Gambar 3. Hal ini sejalan dengan keinginan semua pemangku kepentingan 
PUSPIPTEK yang terdiri dari Kemenristek, BPPT, BATAN dan LIPI dimana pengelolaan yang memaksimalkan peran fungsi masing-masing LPNK menjadi sangat penting dalam mewujudkan Kawasan Eko-inovasi.

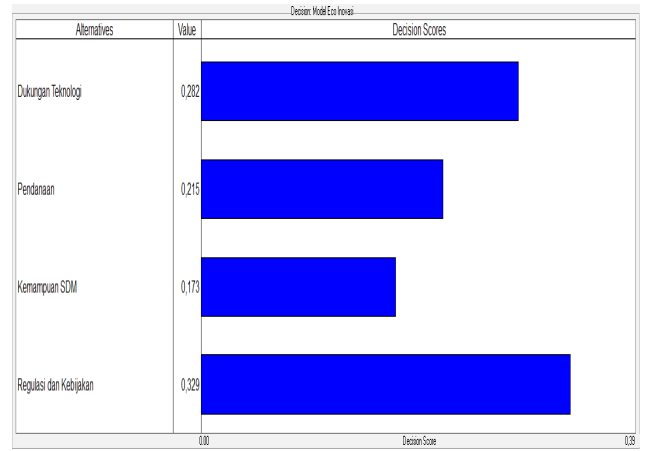

Gambar 3 Hasil pengolahan AHP prioritas pengelolaan kawasan eko-inovasi

Hasil analisis AHP ini sejalan dengan kondisi di PUSPIPTEK yang terdiri dari Pusat/Balai/ Laboratorium dibawah BATAN, LIPI, BPPT, KLH dan Kemenristek. Sehingga pengelolaan partnership menjadi sistem yang sangat sesuai dengan kawasanPUSPIPTEK karena pendanaan eko-inovasi dapat dilakukan berdasarkan sharing pendanaan dari masing-masing instansi yang terlibat dengan Kepala PUSPIPTEK sebagai Kepala Pengelolaan Kawasan.

Pengelolaan kawasan PUSPIPTEK dengan sistem partnership merupakan sistem yang dapat diimplementasikan dengan baik di Kawasan PUSPIPTEK mengingat sistem pengelolaan tersebut akan memungkinkan dilakukannya kerjasama yang baik dari seluruh balai/pusat/laboratorium yang terlibat di bawah satu koordinator yang jelas. Adanya model partnership memungkinkan terjadi sinergi serta meminimalkan terjadinya konflik antar penghuni kawasan karena semua penghuni memiliki peran dan tanggung jawab dalam mengelola kawasan baik secara internal di dalam balai/pusat/laboratorium serta berkontribusi dalam pengelolaan kawasan PUSPIPTEK secara effisien dan effektif serta akan terjadi sharing ilmu pengetahuan dan sekaligus implementasi berbagai hal secara kemitraan.

Pada penelitian ini terdapat 17 permasalahan yang terkait dengan kelembagaan pengembangan eko-inovasi di Kawasan PUSPIPTEK baik langsung maupun tidak langsung. Adapun permasalahan-permasalahan tersebut dapat dilihat pada Tabel 1 dan gambaran dari masingmasing peringkat permasalahan berdasarkan nilai driver power dapat dilihat pada Gambar 4.Berdasarkan Gambar 4, nilai driver power permasalahan tertinggi terdapat pada nomor 7 atau partisipasi pemangku kepentingan untuk perbaikan lingkungan, sedangkan yang memiliki nilai driver power terendah adalah permasalahan nomor 17 atau banyaknya limbah organik dan an-organik yang dihasilkan. Permasalahanpermasalahan tersebut selanjutnya dikelompokkan ke dalam empat sektor yakni autonomous, dependent, linkage, dan independent.
Tabel 1 Permasalahan dalam kelembagaan pengembangan eko-inovasi di Kawasan

\begin{tabular}{|c|c|c|c|c|}
\hline No & Permasalahan & $\begin{array}{l}\text { Driver } \\
\text { Power }\end{array}$ & Rank & Level \\
\hline 1 & Peralatan yang idle dan tua & 4 & 6 & 2 \\
\hline 2 & $\begin{array}{l}\text { Tingkat pelayanan pengguna } \\
\text { kawasan }\end{array}$ & 4 & 6 & 2 \\
\hline 3 & Pertumbuhan kawasan & 6 & 5 & 3 \\
\hline 4 & Pertumbuhan penduduk & 10 & 4 & 4 \\
\hline 5 & Kualitas SDM & 13 & 3 & 5 \\
\hline 6 & Sistem perencanaan kawasan & 16 & 2 & 6 \\
\hline 7 & $\begin{array}{l}\text { Partisipasi pemangku } \\
\text { kepentingan untuk perbaikan } \\
\text { lingkungan }\end{array}$ & 17 & 1 & 7 \\
\hline 8 & Biaya pemulihan lingkungan & 16 & 2 & 6 \\
\hline 9 & $\begin{array}{l}\text { Revisi kebijakan pengadaan } \\
\text { IPAL terpadu }\end{array}$ & 10 & 4 & 4 \\
\hline 10 & Peran pemerintah & 10 & 4 & 4 \\
\hline 11 & $\begin{array}{l}\text { Pengaturan pembuangan } \\
\text { limbah }\end{array}$ & 13 & 3 & 5 \\
\hline 12 & Tenaga keamanan kawasan & 10 & 4 & 4 \\
\hline 13 & $\begin{array}{l}\text { Kepedulian perilakupemangku } \\
\text { kepentingan kawasan }\end{array}$ & 16 & 2 & 6 \\
\hline 14 & Pelayanan pengelola kawasan & 4 & 6 & 2 \\
\hline 15 & $\begin{array}{l}\text { Perilaku pemangku } \\
\text { kepentingan kawasan terhadap } \\
\text { lingkungan }\end{array}$ & 13 & 3 & 5 \\
\hline 16 & $\begin{array}{l}\text { Teknologi / kualitas } \\
\text { lingkungan }\end{array}$ & 6 & 5 & 3 \\
\hline 17 & $\begin{array}{l}\text { Banyaknya limbah organik dan } \\
\text { an-organik yang dihasilkan }\end{array}$ & 1 & 7 & 1 \\
\hline
\end{tabular}

\section{Puspiptek}

Adapun permasalahan prioritas dalam kelembagaan pengembangan eko-inovasi di kawasan PUSPIPTEK adalah : (1) Partisipasi pemangku kepentingan untuk perbaikan lingkungan, (2) Sistem perencanaan kawasan, (3) Biaya pemulihan lingkungan, (4) Keperdulian perilaku pemangku kepentingan kawasan, (5) Kualitas SDM, dan (6) Pengaturan pembangunan pengolahan limbah terpadu.

Hasil analisis ISM menggambarkan pendapat para ahli bahwa prioritas kegiatan dalam penyusunan strategi pengelolaan Kawasan EkoInovasi yang berkelanjutan terdiri dari komponen struktur. Komponen struktur tersebut dibagi menjadi tiga elemen utama yaitu elemen dependent, elemen linkage dan elemen independent.Adapun hasil analisis ISM dapat dilihat pada matriks Driver Power-Dependence seperti yang tertera pada Gambar 6.Pada Gambar 5terlihat bahwa level yang termasuk pada elemen independent adalah level 7 hingga level 5 yang diawali di level 7 yaitu partisipasi pemangku kepentingan untuk perbaikan lingkungan. Level 6 diikuti oleh sistem perencanaan kawasan, biaya pemeliharaan lingkungan dan kepedulian perilaku pemangku kepentingan kawasan. Pada level 5 adalah kualitas SDM, pengaturan pembuangan limbah dan perilaku pemangku kepentingan kawasan terhadap lingkungan. Enam permasalahan prioritas berada pada sektor independent dengan faktor pendorong 
yang besar. Oleh karena itu, keenam elemen ini merupakan elemen-elemen yang paling menentukan dalam penyusunan strategi kelembagaan pengelolaan eko-inovasi yang berbasis kawasan.

Sektor linkage memberikan makna setiap tindakan pada sub elemen akan memberikan dampak terhadap sub elemen lainnya dan pengaruh umpan baliknya dapat memperbesar dampak. Posisi elemen prioritas menumbuhkan kemampuan mandiri dalam upaya hidup sehat, berada di dekat sektor linkage, yang berarti faktor tersebut dapat berubah menjadi sektor linkage apabila faktor-faktor yang lain mendukung sub elemen tersebut. Hasil analisis di sektor linkage berisi elemen pada level ke empat yaitu pertumbuhan penduduk, revisi kebijakan pengadaan IPAL, peran pemerintah dan tenaga keamanan kawasan.

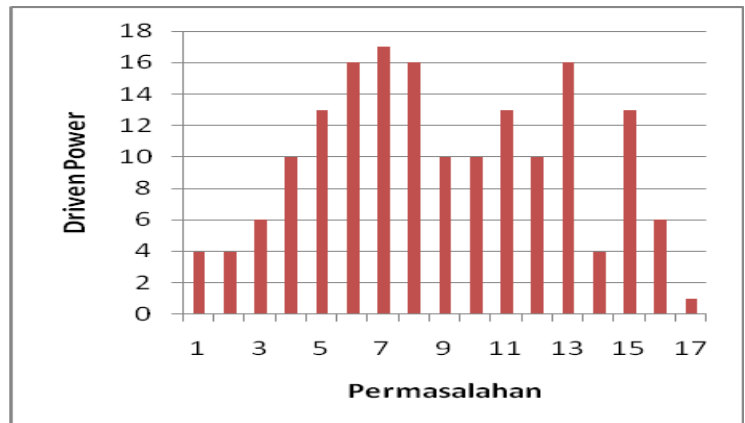

Gambar 4 Peringkat permasalahan berdasarkan nilai driver power

Sektor dependent yang berisi elemen pada level 3 hingga level 1, memberikan makna bahwa keenam elemen prioritas tersebut sangat tergantung pada sistem dan tidak mempunyai kekuatan penggerak yang besar. Level 3 adalah pertumbuhan kawasan dan teknologi / kualitas lingkungan. Pada level 2 terdiri dari peralatan yang sudah idle dan tua, tingkat pelayanan pengguna kawasan dan pelayanan pengelola kawasan. Terakhir pada level 1 adalah banyaknya limbah organik dan anorganik yang dihasilkan.

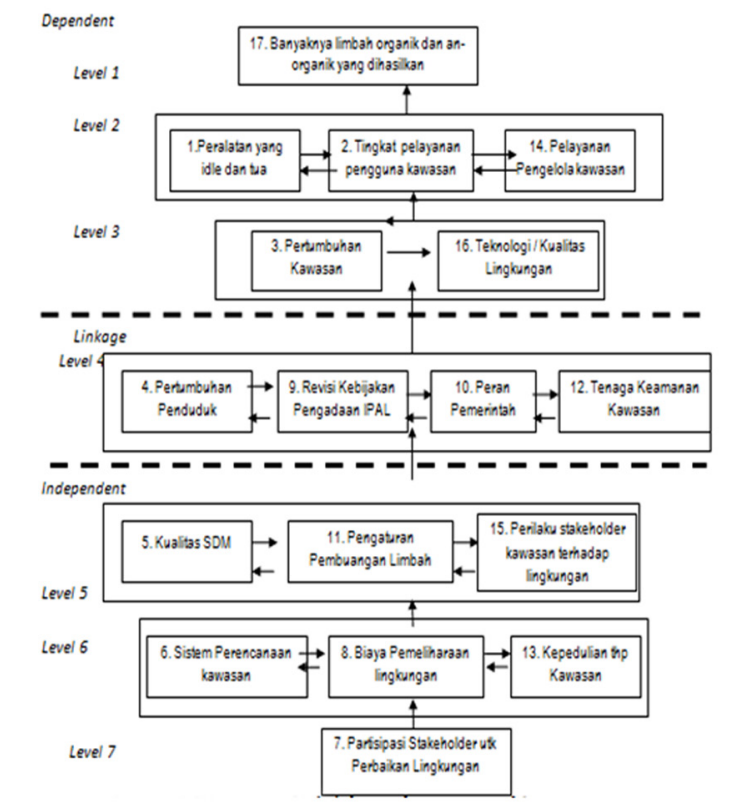

Gambar 5 Diagram hirarki dari elemen-elemen permasalahan
Pada Gambar 5 diperlihatkan bahwa partisipasi stakeholder untuk perbaikan lingkungan dianggap merupakan hal yang utama oleh responden dalam kegiatan pengelolaan kawasan eko- inovasi. Menurut Blake dan Broofield (1987), pemangku kepentingan perlu diletakkan sebagai land manager atau menjadi pusat pengaturan setiap permasalahan dan berdasarkan persepsi dasar masyarakat. Karena menurut Kartasasmita (1996), pembangunan memang dapat berjalandengan mengandalkan kekuatan yang ada pada pemerintah, namun hasilnya tidak akan sama jika dibandingkan dengan pembangunan yang mendapat dukungan dan partisipasi pemangku kepentingan. Dengan demikian perjalanan dalam pembangunan menunjukkan bahwa untuk berhasilnya pembangunan, sangat diperlukan partisipasi pemangku kepentingan.

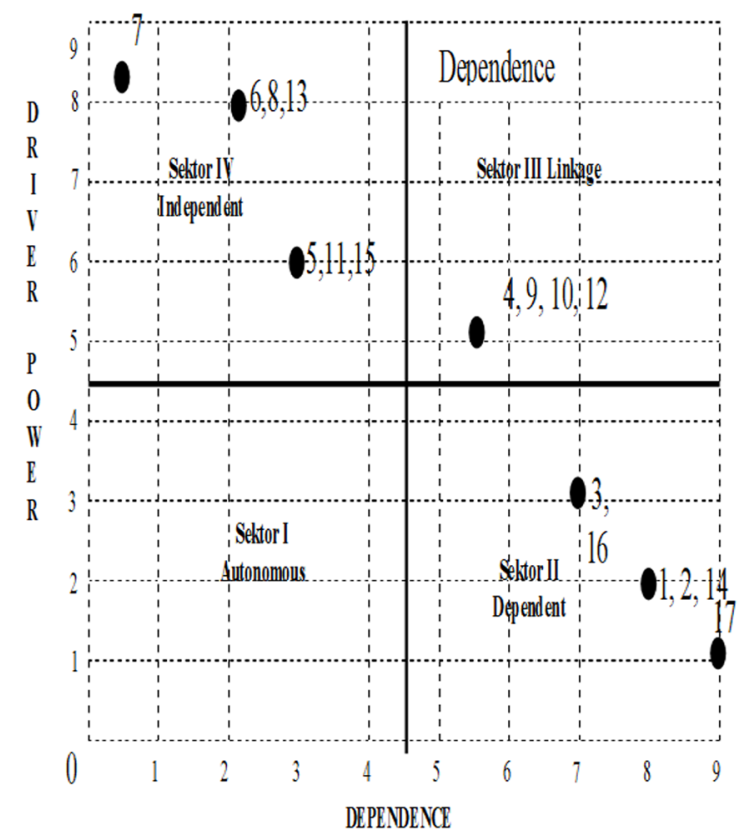

Gambar 6 Matrik driver power-dependence untuk elemen prioritas

Prioritas kegiatan berikutnya adalah sistem perencanaan kawasan kegiatan dibutuhkan untuk meminimalkan biaya dan kesalahan di lapangan dalam bentuk konsep kegiatan, sehingga biaya pemeliharaan kawasan pun dapat ditekan dengan mengutamakan kegiatan sesuai dengan konsep ekoinovasi pada pengelolaan air, limbah dan energi yang telah dibuat sebelumnya. Dengan adanya partisipasi pemangku kepentingan kawasan berupa pikiran, tenaga, keahlian, maupun finansial, maka kepedulian pemangku kepentingan pada pengelolaan kawasanpun dapat ditingkatkan dan lebih memiliki daya ungkit yang tinggi. Hal tersebut sesuai dengan Peraturan Pemerintah Nomor 69 tahun 1996 tentang Pelaksanaan Hak dan Kewajiban, serta Bentuk dan Tata Cara Peran Serta Masyarakat dalam Penataan Ruang yang merupakan salah satu bentuk pengakuan legal akan perlunya partisipasi masyarakat.

Berdasarkan hasil identifikasi pada elemen pelaku eko-inovasi kawasan PUSPIPTEK diperoleh hasil 
bahwa elemen ini terdiri dari empat belas sub elemen pelaku/pemangku kepentingan yang terlibat yaitu:

1. Pemerintah pusat (G-1): Kementerian Riset dan Teknologi merupakan Kementerian yang mempunyai tugas pokok dan fungsi kebijakan IPTEK dan penanggungjawab kawasan PUSPIPTEK melalui Asdep Penyedia dan pengguna iptek.

2. Pemerintah pusat terkait (G-2): BAPPENAS, Kemenperin, Kemenkeu merupakan kementerian yang terkait dengan pendanaan, pembinaan industri dan kebijakan terkait.

3. Pemerintah pusat terkait lingkungan (G-3): KLH Cq Pusarpedal di Kawasan, merupakan pusat sarana pengujian dan pengendalian lingkungan dan jasa konsultasi lingkungan.

4. Pemerintah daerah (G-4): Kota Tangerang Selatan dan Kabupaten Bogor.

5. Pengelola kawasan (G-5): Asdep Jaringan Penyedia dengan Pengguna Iptek dengan tugas merumuskan rekomendasi kebijakan jaringan Iptek, mengimplementasi dan mengevaluasi kebijakan dan memfasilitasi koordinasi LPNK di bawah koordinasi Iptek.

6. Lembaga Litbang (BPPT, LIPI, BATAN) di Kawasan PUSPIPTEK (G-6): sebagai lembaga penelitian, pengujian dan administrasi pelayanan pengguna Iptek.

7. Perguruan tinggi (G-7): sebagai mitra untuk dapat mengembangkan Iptek dan sumber SDM.

8. Industri/IKM (swasta) sebagai pengguna jaringan iptek (G-8).

9. Investor/lembaga keuangan/modal ventura, sebagai sumber pendanaan bagi IKM (G-9).

10. Masyarakat sekitar (G-10): sebagai pihak yang merasakan dampak secara langsung adanya kawasan PUSPIPTEKmerupakan faktor yang tidak boleh dilupakan karena akan sangat menentukan dimana kawasan itu berada maka akan sangat terkait dengan kondisi masyarakat sekitar tanpa dukungan masyarakat sekitar maka suatu sistem tidak akan dapat berjalan.

11. Peneliti/perekayasa Lembaga Litbang di Kawasan (G-11): merupakan SDM yang bertugas untuk menjalankan fungsi penelitian, pelayanan dan fasilitasi industri.

12. Pemanfaat jasa wisata iptek (mahasiswa/SLTA/ SLTP/SD/umum) (G-12):merupakan pihak pengguna kawasan PUSPIPTEK.

13. Lembaga Standarisasi Penilai Eko-Kawasan (GBCI) (G-13): merupakan lembaga yang menilai kawasan dari segi eko.

14. Pengguna jasa PUSPIPTEK (G-14): ( jasa konsultasi, jasa analisa, diklat), merupakan pihak pengguna jasa PUSPIPTEK.

Berdasarkan analisis dengan menggunakan teknik ISM, maka elemen pelaku pengembangan yang terdiri dari 14 sub elemen dapat digambarkan dalam bentuk hirarki dan dibagi dalam empat sektor. Hasil analisis menunjukkan bahwa Kemenristek (G1), Pengelola kawasan (G-5) dan Lembaga
Litbang (G-6) merupakan sub elemen kunci dalam pengembanganeko-inovasi kawasan PUSPIPTEK sehingga perlu dikaji lebih hati-hati karena sub elemen ini akan mendukung pelaku yang lain. Berdasarkan pemisahan tingkat pada reachability matriks, maka dapat dilakukan penetapan hirarki melalui ranking dengan merujuk pada aspek driver power. Diagram model struktur elemen pelaku pengembangan dapat dilihat pada Gambar 7. Struktur hirarki menunjukan hubungan langsung dan kedudukan relatif antar sub elemen pelaku pengembangan.Hal ini berarti bahwa sub elemen pelaku pengembangan yang satu akan didukung oleh sub elemen pada hirarki dibawahnya.

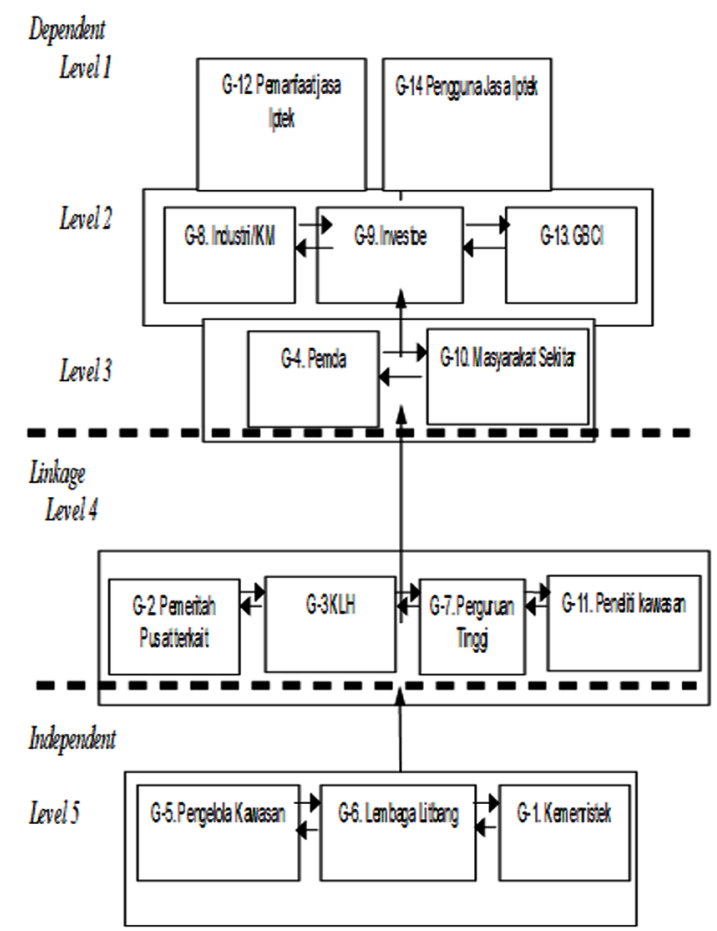

Gambar 7 Diagram hirarki dari elemen-elemen pelaku/pemangku kepentingan

Berdasarkan matrik driver power dan dependence maka dapat dikelompokkan kedalam empat sektor sebagaimana dapat dilihat pada Gambar 8. Sektor I merupakan sektor autonomous, sektor II merupakan sektor dependent, sektor III merupakan sektor lingkage dan sektor IV merupakan sektor independent.

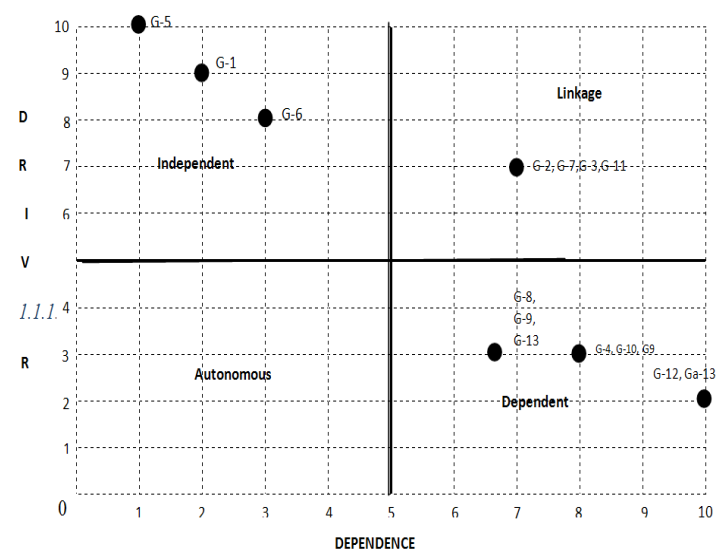

Gambar 8 Matrik driver power-dependence pelaku/ pemangku kepentingan 
Berdasarkan matrik driver power dan dependence menunjukan bahwa sub pemerintah pusat terkait (G-2), KLH (G-3), perguruan tinggi (G-7) dan peneliti kawasan (G-11) merupakan sektor linkage. Hal ini berarti sub elemen ini mempunyai kekuatan penggerak tinggi tetapi mempunyai tingkat ketergantungan yang tinggi terhadap elemen pelaku yang lain. Pada setiap tindakan pada sub elemen ini akan menghasilkan sukses pengembangan eko-inovasi, sedangkan lemahnya tindakan pada sub elemen ini akan menyebabkan kegagalan pengembangan program ini, oleh karena itu maka sub elemen ini perlu dikaji secara hati-hati. Sub elemen pengelola kawasan (G-5), lembaga litbang (G-6) dan Kemenristek (G1) berdasarkan klasifikasi tersebut tergolong dalam kelompok independent. Hal ini menunjukan bahwa sub elemen ini mempunyai kekuatan pendorong yang tinggi tetapi tingkat ketergantungan terhadap pengembangan eko-inovasi tinggi.Analisis lebih lanjut menyatakan bahwa pemda (G-4), masyarakat sekitar (G-10), industri/IKM (G-8), Investor (G-9), GBCI (G-13), pemanfaat iptek (G-12) dan pengguna jasa iptek (G-14) adalah termasuk peubah bebas (dependent). Dalam hal ini berarti mempunyai kekuatan penggerak yang rendah dan tingkat ketergantungan tinggi, sehingga sub elemen ini merupakan akibat dari sub elemen yang lain.

\section{Model struktur lembaga}

Untuk dapat mewujudkan kawasan PUSPIPTEK sebagai kawasan ekologis maka diperlukan upayaupaya proaktif diberbagai aspek yang menyangkut kebijakan, kelembagaan, partisipasi masyarakat serta unsur lainnya yang dapat mendukung terwujudnya kawasan eko-inovasi PUSIPTEK. Kelembagaan secara umum dapat ditinjau dari 2 (dua) aspek meliputi aspek kelembagaan dan aspek keorganisasian. Aspek kelembagaan berkaitan dengan norma, nilai, kebiasaan. Pada aspek kelembagaan perubahannya bersifat kultural dan berlangsung lama.Sedangkan aspek keorganisasian menekankan pada struktur atau struktur sosial yang menitikberatkan pada aspek peran, aktivitas, hubungan antar peran, integrasi sosial. Pada aspek keorganisasian bersifat struktural dan perubahan sosial berlangsung cepat. Dari pengertian di atas, maka penelitian ini melihat dari kedua aspek tersebut.

Sistem pengelolaan dan struktur lembaga eko-inovasi di kawasan PUSPIPTEK disusun berdasarkan hasil analisis data AHP dan ISM. Pada pemilihan sistem pengelolaan kawasan yang merupakan pilihan terbaik adalah model partnership dan Kemenristek (G1), Pengelola kawasan (G-5) dan Lembaga Litbang (G-6) merupakan sub elemen kunci dalam pengembangan eko- inovasi Kawasan PUSPIPTEK sehingga perlu dikaji lebih hati-hati karena sub elemen ini akan mendukung pelaku yang lain. Sesuai dengan kondisi kelembagaan saat ini serta permasalahan yang dihadapi pengelola PUSPIPTEK maka layaknya sebuah kawasan pada umumnya memiliki entitas khusus dimana kawasan PUSPIPTEK secara fungsional memiliki ciri tertentu/ spesifik dan khusus. Mizany et al. (2008) menyatakan bahwa kawasan khusus dapat dicirikan oleh 4 (empat) karakteristik umum yakni; a. A form of government, $b$. Governed by a board, c. Provide services and facilities dan d. Has defined boundaries. Oleh karena itu, dalam menyelenggarakan fungsi pemerintahan tertentu yang bersifat khusus melalui kawasan khusus seperti halnya PUSPIPTEK dibutuhkan adanya lembaga yang menyelenggarakan fungsi pemerintahan tersebut.

Implementasi model partneship pada kawasan PUSPIPTEK memiliki kompleksitas yang tinggi tercermin dari permasalahan yang dihadapi serta para pemangku kepentingan yang berpengaruh terhadap pengelolaan PUSPIPTEK. Untuk menjawab hal tersebut diperlukan adanya struktur lembaga yang berfungsi optimal agar terjadi sinergi antara pengelola kawasan dan lembaga litbang serta pemangku kepentingan lainnya. Sedangkan pertimbangan model kelembagaan kawasan khusus PUSPIPTEK secara desentralisasi sebagai berikut; Untuk menjawab hal tersebut diperlukan adanya struktur lembaga yang berfungsi optimal agar terjadi sinergi antara badan pengelola kawasan dan lembaga litbang serta pemangku kepentingan lainnya. Sedangkan pertimbangan model kelembagaan kawasan khusus PUSPIPTEK secara desentralisasi sebagai berikut; 1 . terciptakemandiriankawasan, karenaBadan Pengelola Kawasan diberikan otonomi dan bersifat independen untuk mengelola sendiri kawasannya; 2. terjadi effisiensi pegawai, karena pegawai yang dibutuhkan sesuai dengan kompetensi yang dibutuhkan; 3 . terjadi pemanfaatan sumber daya lainnya termasuk dana karena Badan Pengelola Kawasan akan bekerja sesuai mendekati skala ekonomi atau paling tidak sesuai dengan lingkup tugas dari kawasan yang dikelolanya serta; 4. terjadi percepatan pertumbuhan kawasan yang mendukung perekonomian lokal, nasional dan regional. Dari sudut pengelolaan secara profesional sesuai Undang-undang Aparatur Sipil Negara (ASN) memberikan peluang rekruitmen terhadap tenagatenaga profesional di bidangnya melalui rekruitmen aparatur sipil negara dengan Pegawai Pemerintah dengan Perjanjian Kerja. Hal ini memberi peluang yang lebih luas agar PUSPIPTEK dikelola dengan prinsip-prinsip managemen modern.

Berdasarkan pertimbangan di atas dan sesuai karakteristik serta permasalahan yang dihadapi serta beban tugas dan fungsi yang diemban oleh PUSPIPTEK dalam mengembangkan kawasan ekoinovasi maka struktur lembaga yang disarankan adalah berupa Badan Pengelola Kawasan. Badan Pengelola Kawasan yang akan dibentuk harus memiliki struktur lembaga yang dapat mengoptimalkan fungsifungsi PUSPIPTEK ke depan baik secara internal mengelola fisik kawasan agar terjadi koordinasi yang harmonis antara pengelola dan para lembaga yang berada di dalam kawasan, sedangkan secara eksternal dapat melakukan pelayanan kepada masyarakat baik pelayanan publik maupun komersialisasi hasil-hasil iptek. Adapun model lembaga PUSPIPTEK sebagai kawasan khusus sebagaimana Gambar 9. 


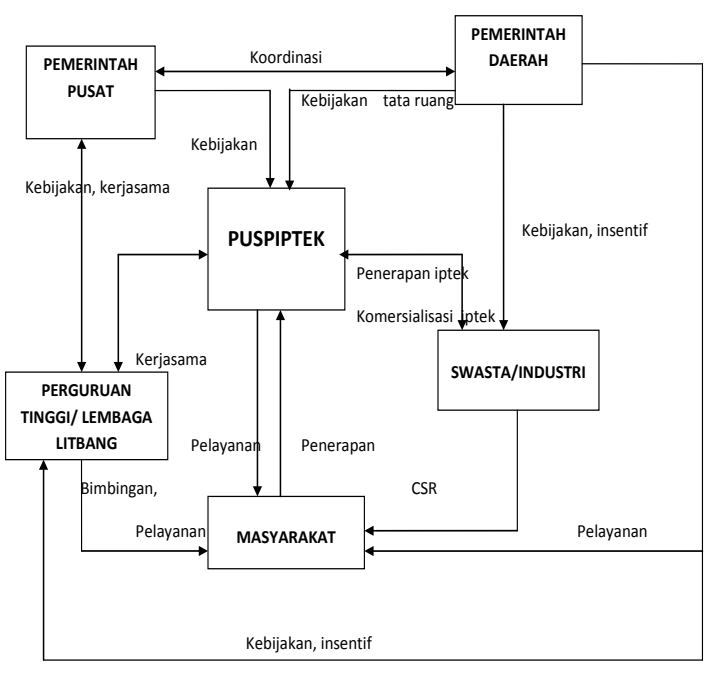

SIMPULAN

Berdasarkan hasil penelitian, model kebijakan pengembangan kawasan eko- inovasi (studi kasus kawasan Pusat Ilmu Pengetahuan dan Teknologi, Kota Tangerang Selatan) disimpulkan sebagai berikut:

1. Hasil pengolahan AHP yang dilakukan berdasarkan penilaian pakar maka model kebijakan pengelolaan kawasan eko-inovasi yang paling sesuai adalah model partnership. Hal ini sejalan dengan keinginan semua stakeholder Puspiptek yang terdiri dari Kemenristek, BPPT, BATAN dan LIPI dimana pengelolaan yang memaksimalkan peran fungsi masing-masing LPNK menjadi sangat penting dalam mewujudkan kawasan ecoinovasi.

2. Struktur lembaga yang optimal untuk dapat melaksanakan konsep eko-inovasi di kawasan PUSPIPTEK adalah berupa Badan Pengelola Kawasan yang dapat berfungsi optimal dalam mengkoordinasikan stakeholder internal maupun eksternal.

\section{Saran}

Beberapa saran penelitian dalam rangka pengembangan kebijakan kawasan ecoinovasi di Kawasan Puspiptek adalah sebagai berikut: Untuk menciptakan keterpaduan kerja dalam mewujudkan kawasan eko inovasi di PUSPIPTEK melalui pengembangan soft infrastruktur. Adapun langkah-langkah yang harus diambil adalah 1) Melakukan restrukturisasi kelembagaan yang saat ini agar memperkuat peran-peran para pemangku kepentingan dalam mengimplemtasikan kebijakan eko inovasi; 2) Perencanaan program dilakukan secara terpadu dengan melibatkan semua pemangku kepentingan dalam kawasan; 3) Mengembangkan instrumen reward dan punsihment dalam meningkatkan partisipasi para pemangku kepentingan yang terlibat; 4) Meningkatkan kemampuan sumber daya manusia dalam manajemen pengelolaan lingkungan melalui pendidikan dan latihan; 5) Melakukan sosialisasi baik secara internal di dalam kawasan maupun ekternal; 6) Melakukan monitoring dan evaluasi; serta 7) Mengembangkan etika penelitian yang berorientasi pada pembangunan berkelanjutan.

\section{DAFTAR PUSTAKA}

Adamides ED, Mouzakitis Y. 2009. Industrial Ecosystem as technologycal niches. Journal of Cleaner Production 17. 172-180.

Alkadri, Dodi, 1999. Manajemen Teknologi Untuk Pengembangan Wilayah, Pusat Pengkajian Kebijakan Teknologi Pengembangan Wilayah, BPPT.

Arifin B. 2012. Ekonomi Hijau: Evolusi Konsep Pembangunan Berkelanjutan. http://barifin. wordpress.com/2012/12/06/ekonomi-hijauevolusi-konsep-pembangunan-berkelanjutan.

Andersen,M.M. 2006. Eco-Innovation Indicator, European Environment Agency, Copenhagen.

Blake,Piers and Brookfield,Harold. 1987. Land Degradation, Edited by Blaikie P and Brookfield $\mathrm{H}$, London, Methuen.

Dye RT. 1992. Understanding Public Policy. Englewood Cliffs,N.J, Prentice Hall

Dawud J.2003. Kelembagaan Wilayah Khusus (special distric), PKDA-LAN. Bandung

Era-Net Eco-Innovera. 2012. International survey on eco-innovation parks; Learnings from experiences on the spatial dimension of eco-innovation, Preliminary Report.

Jones E, Harrison D, McLaren. 2001. Managing Creative Eco-innovation: Structuring outputs from Ecoinnovation from Eco-innovation projects. The Journal of Sustainable Product Design Vol:1, Issue 1 (27-39).

Kartasasmita, G. Pembangunan Untuk Rakyat : Memadukan Pertumbuhan dan Pemerataan. Cidis Jakarta.

Marimin. 2004. Teknik dan Aplikasi Pengambilan Keputusan Kreteria Majemuk, Grasindo, Jakarta

Mizany K, Mannat A. 2008. What So Special About Special District? A Citizen's Guide to Special District in California, third ed, www.csda.net.

Nugraha R. 2004. Kebijakan Publik; Formulasi, Implementasi dan Evaluasi, PT Gramedia, Jakarta.

OECD.2009 Sustainable Manufacturing and ecoinnovation:Framework,Practices and MeasurementSynthesis Report,OECD,Paris

OECD.2011. Oslo Manual: Guidelines for collecting and Interpreting Innovation Data, $3^{\text {rd }}$ Edition.

Pansera M. 2013. The Origins and Purpose of EcoInnovation. International Journal of Innovation and Sustainable Development (1)/2013;7(1):27-4 5.

Sarkar AN. 2013.Promoting Innovations to Leverage Sustainable Development of Eco-industry and Green Growth. European Journal of Sustainable Development (2013),2,1,171-224 
Pengembangan Kebijakan Kawasan Eko-Inovasi (Studi Kasus Kawasan Pusat Ilmu Pengetahuan dan Teknologi, Kota Tangerang Selatan) Sri Setiawati, Hadi Alikodra, Bambang Pramudya, dan Arya Hadi Dharmawan

Sakr,D, et al. 2011. Critical success and limiting factors for eco-industrial parks:global trends and Eqyptian context. Journal Clean Production,19 (11), 1158-1169

Tian,Jinping, et al, 2013. Study of the performance of eco-industrial park development in China, Journal of Cleaner Productionxxx(2013)1-9
The Constitution of the Republic of Indonesia of 1945

Zaenuri. 2009. Environmental Management of Industry Model Through Eco-EfiisiencySamongan Industrial Park in Semarang City, Report of Research Insentif of Doctoral Program 2009. 